\title{
PUSAT KEGIATAN KAUM MILLENIAL
}

\author{
Denny Kusuma ${ }^{1)}$ \\ 1) Program Studi S1 Arsitektur, Fakultas Teknik, Universitas Tarumanagara, drake_kusuma@hotmail.com
}

\begin{abstract}
Abstrak
Salah satu karakteristik millennial adalah kreatif, di mana kreativitas millennial ini belum tersalurkan secara maksimal dengan adanya wadah-wadah yang dapat menampungnya, sedangkan pendorong utama industri kreatif utama saat ini adalah generasi millennial tersebut. Pemerintah pun mulai menyadari akan pentingnya industry kreatif ini untuk mendorong perekonomian negara. Oleh karena itu maka pemerintah mulai membuat wadah-wadah untuk menampung dan juga mendorong generasi millennial ini untuk menyalurkan hingga akhirnya membentuk perusahaan-perusahaan baru dalam bidang industri kreatif. Pusat Kegiatan Kaum Millenial atau Millennial Hub yang terletak di Grogol ini difungsikan sebagai wadah bagi generasi millennial untuk saling berbagi, mengembangkan dan menyalurkan ide dan kreativitas mereka hingga akhirnya mereka dapat membentuk dan menghasilkan perusahaan start-up maupun sesuatu yang berguna untuk meningkatkan ekonomi kreatif baik skala nasional maupun internasional. Di dalam Pusat Kegiatan Kaum Millenial ini terdapat 2 program utama yaitu Balai Millennial dan Pusat Kreativitas dimana kedua program ini saling mendukung satu dengan lainnya dimana Pusat Kreativitas difungsikan sebagai wadah bagi generasi millennial untuk menyalurkan dan mengembangkan kreativitasnya, sedangkan Millennial Hall difungsikan sebagai wadah bagi mereka untuk menunjukkan hasil dari kreativitasnya tersebut hingga diketahui dan diakui oleh masyarakat dan dapat dibantu kembangkan hingga skala nasional maupun internasional.
\end{abstract}

Kata kunci: balai millennial; kreativitas; pusat kreativitas

\begin{abstract}
One of the characteristics of millennials is being creative. However, this creativity has not been utilized fully due to the absent of spare rooms to be used, whilst the main drive of creative industry is millennials themselves. The government begins to realize the importance of the emergent creative industry that can play a big role in the overall economy of the country. So, the government is currently trying to provide various spaces to accommodate them, likewise supporting them to open up to possibilities and innovation that drives them towards the creation of start-up companies. Millennial Hub that is situated at Grogol functions as a space for millennials to coshare, co-develop, open up ideas and creativity in order to assemble start-up companies or innovative produces that can increase the creative economy on a nationwide or global scale. Here, there are two main programs: millennial hall and creative hub. Both spaces support each other creative hub functions as a space for the millennial generation to develop their creativity, meanwhile millennial hall functions as a space for them to exhibit their own creative innovations so as to be acknowledged by the public that can help in the investment on the nation or global scale.
\end{abstract}

Keywords : creative hub; creativity; millennial hall

\section{PENDAHULUAN}

Masyarakat DKI Jakarta terutama generasi milenial memiliki kreativitas yang tinggi, namun belum banyak tempat untuk menyalurkan dan mengekspresikan kreativitas mereka sehingga banyak dari kreativitas yang harusnya dapat menjadi berguna bagi perkembangan ekonomi kreatif ini menjadi tidak tersalurkan dan terpendam. Oleh karena itu dibutuhkan wadah untuk menyalurkan, mengembangkan dan mengekspresikan kreativitas masing-masing individu yang ada. 
Telah banyak berkembang perusahaan-perusahaan industri kreatif yang telah berkembang pesat dan turut berkontribusi untuk meningkatkan ekonomi negara seperti contohnya Tokopedia, Go-Jek, Traveloka dan masih banyak lagi. Oleh karena itu perkembangan industri kreatif harus terus didukung baik oleh pemerintah maupun swasta.

Ruang kerja terbuka kini makin banyak tersedia, terutama di Jakarta. Itupun seperti belum cukup, mengingat saat ini juga tambah banyak anak-anak muda Indonesia yang membutuhkannya, terutama mereka yang bergelut di industri kreatif. Pemerintah juga telah turut berkontribusi untuk mengembangkan industri kreatif yaitu melalui Badan Ekonomi Kreatif (BEKRAF) dengan menyediakan sarana ruang kreatif bagi penduduk Indonesia yang utamanya adalah usia produktif yang dikuasai oleh generasi milenial. Oleh karena itu diusulkan untuk dibangun Millenial Hub ini untuk menjadi wadah bagi generasi milenial untuk meningkatkan kreativitas mereka hingga akhirnya dapat turut membantu meningkatkan ekonomi kreatif nasional maupun internasional.

\section{KAJIAN LITERATUR}

\section{Generasi Milenial}

Millennials atau kadang juga disebut dengan generasi $Y$ adalah sekelompok orang yang lahir setelah Generasi X, yaitu orang yang lahir pada kisaran tahun 1980- 2000an. Millennials sendiri dianggap spesial karena generasi ini sangat berbeda dengan generasi sebelumnya, apalagi dalam hal yang berkaitan dengan teknologi. Generasi millennials memiliki ciri khas tersendiri yaitu, mereka lahir pada saat TV berwarna,handphone juga internet sudah diperkenalkan. Sehingga generasi ini sangat mahir dalam teknologi.

Berikut adalah 6 karakteristik generasi milenial menurut Sally Kane penulis dari The Balance Careers (2019):

a. Berpaku pada teknologi

Generasi milenial tidak bisa lepas dengan teknologi. Bahkan kesehariannya generasi milenial bisa menghabiskan waktu 7-9 jam setiap harinya pada teknologi.

b. Lebih mementingkan waktu dengan keluarga

Generasi milenial mencari pekerjaan yang memiliki waktu yang lebih fleksibel agar dapat menghabiskan waktu lebih banyak dengan orang-orang dekatnya. Mereka lebih mementingkan keluarga dibandingkan pekerjaannya.

c. Mementingkan pencapaian

Generasi milenial lebih percaya diri, berambisi dan lebih mementingkan pencapaian dan memiliki ekspektasi yang tinggi dan tidak takut untuk mencoba hal-hal baru.

d. Suka berkolaborasi

Generasi milenial ingin untuk dianggap dan ikut berpartisipasi dalam suatu pekerjaan dan lebih menghargai rekan kerjanya.

e. Haus akan perhatian

Generasi milenial menghargai akan pujian dan jaminan. Generasi milenial akan mendapatkan lebih banyak hal dari mentor yang membimbingnya untuk mengembangkan talentanya. Disinilah peran generasi baby-boomers bagi generasi milenial diperlukan.

f. Suka berpindah-pindah pekerjaan

Generasi milenial selalu mencari suatu hal yang baru dan lebih baik sehingga memiliki banyak pengalaman yang berbeda dan umumnya tidak bisa menetap di satu pekerjaan yang sama untuk jangka waktu yang lama. 


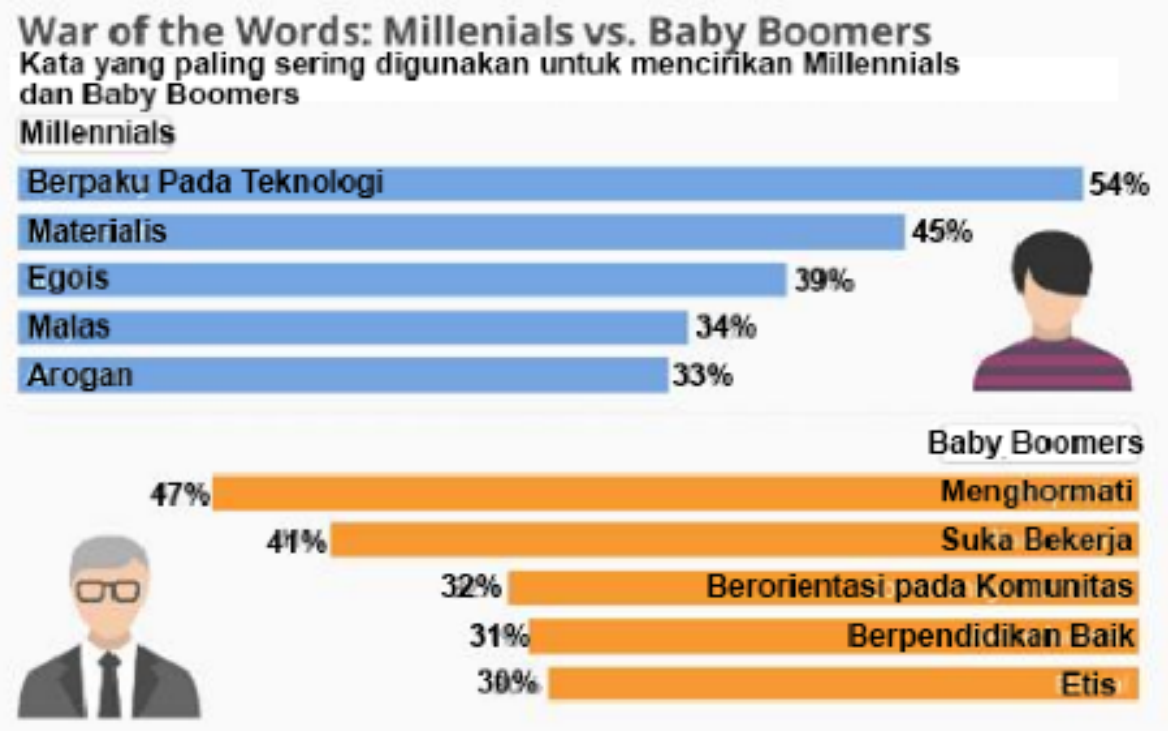

\section{statista 5}

Gambar 1. Perbandingan Sifat Milenial dan Baby Boomers Sumber: Diterjemahkan dari Statista 26 Juni 2017

\section{Hubungan Antara Arsitektur-Tipe-Perilaku serta Nilai Kesejamanan}

Menurut Alvara Research Center, generasi milenial memiliki 3 sifat yaitu yang pertama adalah kreatif, mereka adalah orang yang biasa berpikir out of the box, kaya akan ide dan gagasan dan mampu mengkomunikasikan ide dan gagasan itu dengan cemerlang. Generasi milenial termasuk generasi yang kreatif, salah satu bukti pendukungnya adalah tumbuhnya industry start up dan industry kreatif lain yang di motori oleh anak muda. Sifat kedua adalah connected yang berarti generasi milenial adalah generasi yang pandai bersosialisasi terutama dalam komunitas yang mereka ikuti, mereka juga aktif berselancar di sosial media dan internet. Sifat ketiga adalah confidence yang berarti mereka sangat percaya diri, berani mengemukakan pendapat dan tidak sungkan-sungkan berdebat di depan publik.

Menurut Majalah Fortune, rata-rata usia generasi milenial yang menjadi usahawan lebih muda daripada generasi Baby Boomer. Generasi yang lebih tua meluncurkan bisnis pertama mereka saat berusia sekitar 35 tahun. Sementara generasi milenial sudah memulai usaha pada umur 27 tahun. Dengan sifat generasi milenial yang kreatif dan lebih cepat dalam memulai usaha, maka generasi ini berpotensi besar dalam meningkatkan ekonomi kreatif negara dan menciptakan lapangan kerja baru termasuk menciptakan industri kreatif.

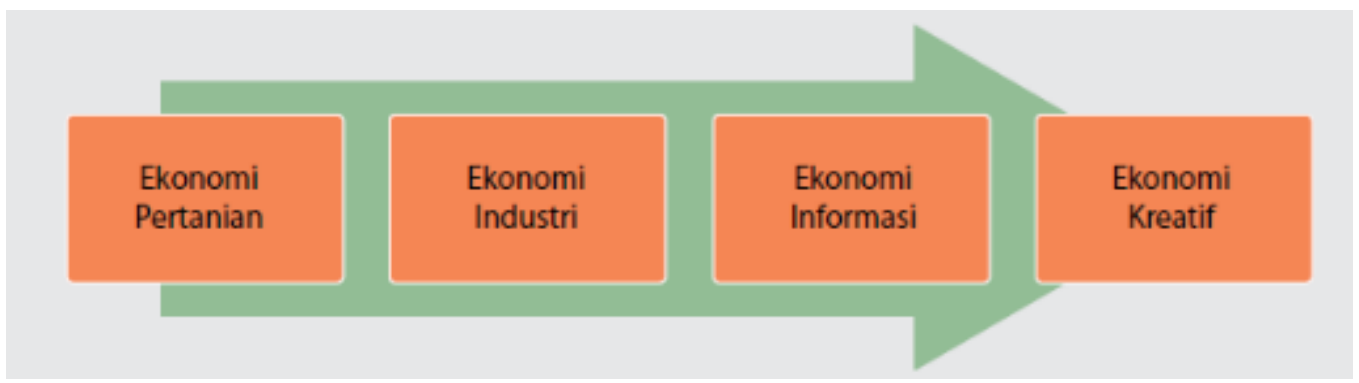

Gambar 2. Perkembangan Ekonomi Seiring Waktu Sumber: Alvara Research Center 
Ekonomi terus berkembang hingga akhirnya sekarang berkembang menjadi ekonomi kreatif dikarenakan perkembangan teknologi hingga akhirnya banyak didukung juga oleh program pemerintah yang bertujuan untuk meningkatkan ekonomi kreatif negara. Hal ini menjadi tuntutan bagi generasi milenial dikarenakan banyaknya generasi milenial yang berumur produktif pada dekade ini. Maka dari itu kekreativitasan milenial disalurkan melalui perusahaan start-up yang merupakan produk dari ekonomi kreatif tersebut.

\section{Kreativitas Milenial}

Menurut Majalah Forbes, generasi milenial sering terobsesi pada diri sendiri atau narsisistik, tetapi kenyataannya adalah, generasi ini cenderung berpikir lebih mandiri dan lebih cenderung lebih berdebat secara kreatif daripada generasi sebelumnya. Dalam beberapa kasus, hal ini bisa menjadi masalah dikarenakan milenial mungkin menuntut lebih banyak fleksibilitas dalam pekerjaannya, atau mungkin lebih cenderung untuk melanggar peraturan yang ada, tetapi hal ini juga membuat mereka lebih mungkin untuk menyumbangkan ide-ide baru tentang bagaimana memperkuat platform keberagaman dalam suatu perusahaan. Sehingga dapat disimpulkan bahwa generasi milenial ini memiliki kreativitas yang tinggi dan memiliki kecenderungan untuk memperhatikan perbedaan yang dimiliki setiap orang. Tidak mengherankan bahwa sebagian besar bisnis yang sukses dan inovatif didukung oleh Generasi Milenial, contohnya seperti Google, Facebook, Snapchat, dan beberapa perusahaan lainnya. Perusahaan-perusahaan ini memiliki tenaga kerja kaum milenial yang memiliki ide-ide yang kreatif untuk membuat inovasi baru.

Robert Lucas mengatakan bahwa kekuatan yang menggerakan pertumbuhan dan pembangunan ekonomi kota atau daerah dapat dilihat dari tingkat produktivitas klaster orang orang bertalenta dan orang-orang kreatif atau manusia-manusia yang mengandalkan kemampuan ilmu pengetahuan yang ada pada dirinya.

Dikarenakan jumlah penduduk sekarang ini yang telah didominasi oleh generasi milenial, maka kontribusi tertinggi ekonomi Indonesia saat ini adalah dari ekonomi kreatif yang banyak diciptakan oleh generasi milenial. Industri kreatif ini merupakan pilar utama dalam pembentukan ekonomi kreatif dan ekonomi kreatif ini sangatlah penting bagi Indonesia karena diyakini ekonomi kreatif akan memberikan dampak positif bagi tatanan kehidupan berbangsa dan bernegara. Industri kreatif juga merupakan salah satu upaya untuk mendukung terbentuknya ekonomi kreatif yang mencakup enam hal yaitu: Kontribusi Ekonomi; Iklim Bisnis; Citra dan Identitas Bangsa; Sumber Daya Terbarukan; Inovasi \& Kreativitas; dan Dampak Sosial. 


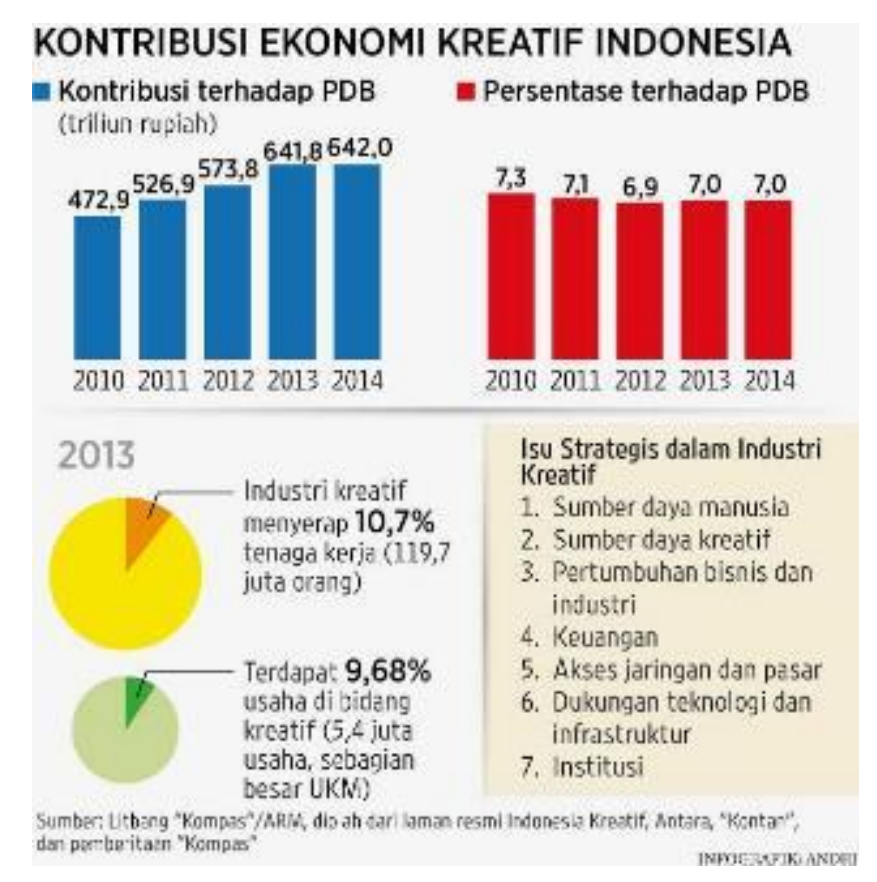

Gambar 3. Persentase Kontribusi Ekonomi Kreatif Indonesia Sumber: Litbang "Kompas"/ARM

Dari data diatas terlihat bahwa kontribusi ekonomi kreatif Indonesia semakin tahun semakin meningkat dan juga industri kreatif memberikan lapangan kerja sebanyak 10,7\% yaitu 119,7 juta orang pada tahun 2013. Dengan demikian industri kreatif menjadi bidang yang paling berpotensi untuk semakin berkembang kedepannya dan generasi milenial berperan besar bagi perkembangan ini.

\section{Tipologi}

Menurut Amine Klam dalam bukunya yang berjudul Space and Material: Towards An Architectural Typology, untuk merancang bangunan, dibutuhkan studi terlebih dahulu untuk mengetahui susunan yang dibutuhkan dalam merancang bangunan tersebut sehingga dapat diketahui program dan menyesuaikannya dengan lingkungan sekitarnya. Studi ini dapat dilakukan dengan mempelajari fungsi bangunan serupa yang ada dan memperhatikan sejarah dan perubahan-perubahan yang terjadi pada bangunan tersebut seiring waktu.

- Tipologi hall:

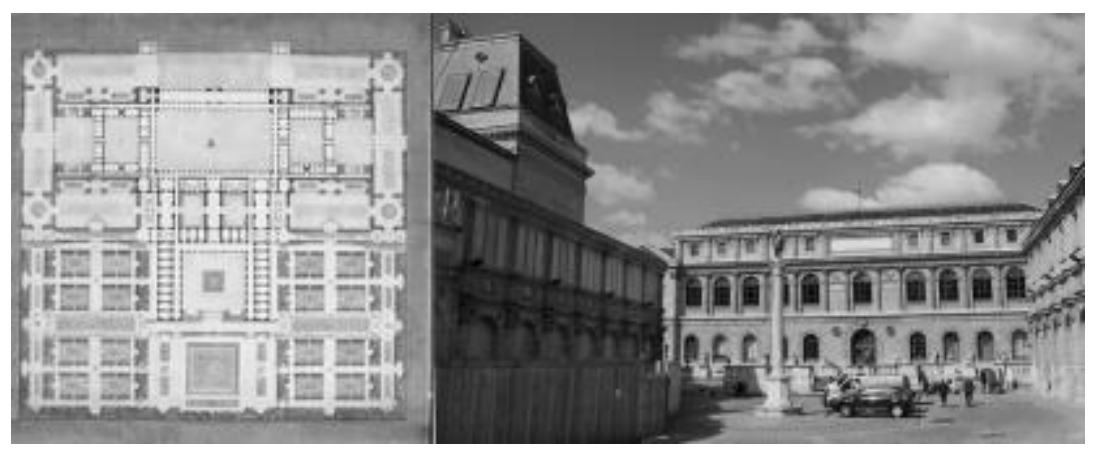

Gambar 4. Academie de Beaux-Arts Tahun 1648

Sumber: Minorsights 


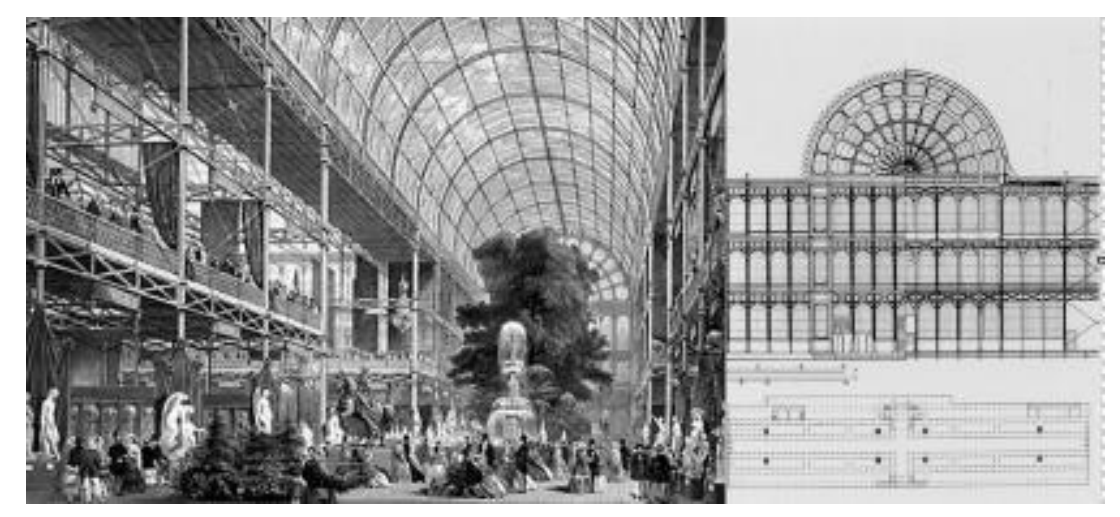

Gambar 5. Crystal Palace World Exhibition Tahun 1851

Sumber: Studyblue

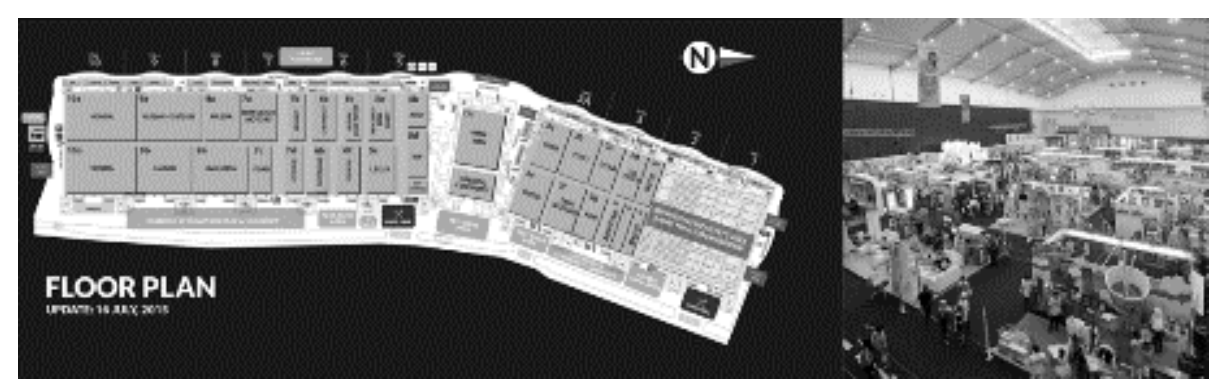

Gambar 6. ICE BSD Tahun 2015

Sumber: Poskotanews, 2016

\section{Tipe}

Tipe menurut Kamus Besar Bahasa Indonesia adalah model atau contoh yang dalam jenis bahasa yang oleh klasifikasi tipologis dianggap mempunyai kemiripan structural, lepas dari sejarah dan lokasi pemakaiannya. Tipe juga dapat dimengerti sebagai kajian atas representasi simbolik, khususnya yang terkait pada asal-usul huruf/aksara dalam Al-Kitab dan pemaknaannya dan merupakan klasifikasi sistematik berdasarkan karakteristik fisik dan sifat bawaannya.

Menurut Raphael Moneo dalam bukunya yang berjudul Oppositions, Tipologi dalam arsitektur dibagi menjadi 3 yaitu:

a. Tipologi berdasar konfigurasi bentuk dan ruang (spatial structure) $=$ firmitas

b. Tipologi berdasar fungsi bangunan = utilitas

c. Tipologi berdasar citra (images)/berdasar langgam (architectural styles) = venustas

Tipologi juga dapat dibagi menjadi 2 yaitu sebagai idea dan sebagai model. Tipe sebagai idea adalah sesuatu yang tidak dapat ditiru dan wujudnya abstrak dan konseptual, sedangkan tipe sebagai model adalah sesuatu yang tidak dapat dikurangi dan prosesnya yang dilakukan oleh setiap individu tidak mungkin sama.

\section{Prototipe}

Prototipe dalam Kamus Besar Bahasa Indonesia diartikan sebagai model yang mulamula (model asli) yang menjadi contoh. Prototipe berfungsi dalam membaca suatu pola yang terjadi dan mempelajari perubahan yang terjadi dari pola tersebut sehingga pola tersebut dapat digunakan dalam mendesain program maupun bentuk bangunan yang akan dibangun. Hal yang dapat dipelajari dari prototipe suatu bangunan adalah melalui massa, denah, dan tampaknya. 


\section{Stereotipe}

Stereotipe dalam Kamus Besar Bahasa Indonesia berarti sesuatu yang berbentuk tetap atau berbentuk klise. Stereotipe dalam arsitektur berarti mempelajari tipe bangunan yang paling umum dalam fungsinya, hanya saja setiap individu dapat berbeda cara pandangnya. Hal yang dapat dipelajari dari stereotipe suatu bangunan adalah melalui massa, denah, dan tampaknya.

\section{METODE}

\section{Survei Lapangan}

Survei ini difungsikan untuk mengetahui kondisi baik di dalam tapak maupun di sekitar tapak dan elemen-elemen apa yang mempengaruhi tapak tersebut.

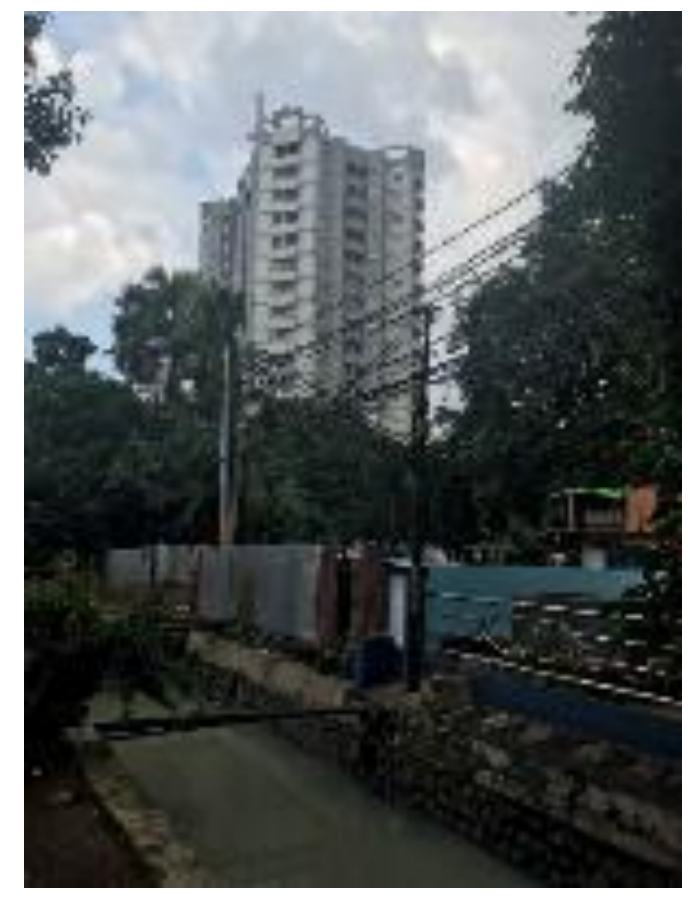

Gambar 7. Bangunan sisi Timur tapak Sumber: Penulis, 2019

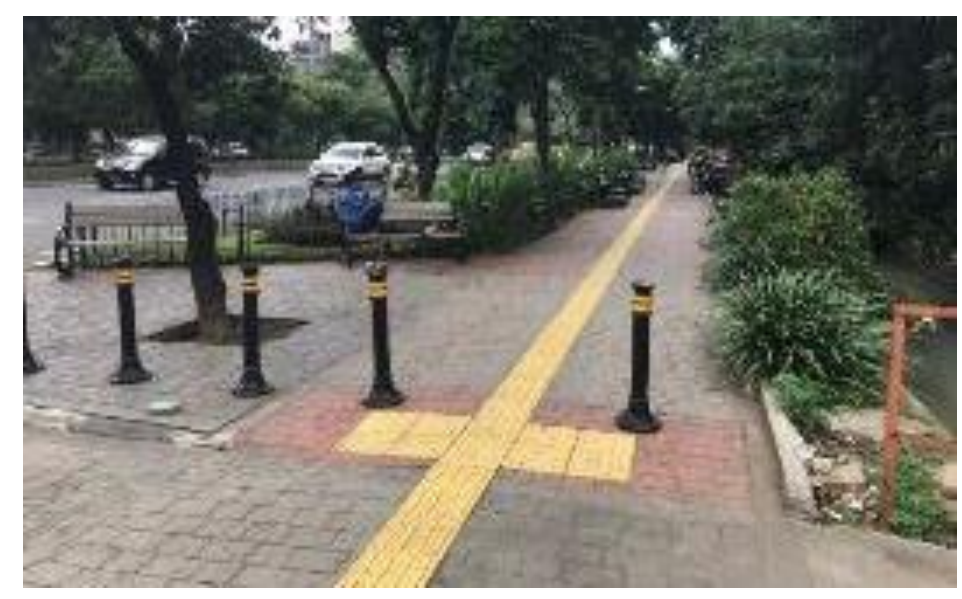

Gambar 8. Kondisi pedestrian di depan tapak Sumber: Penulis, 2019 


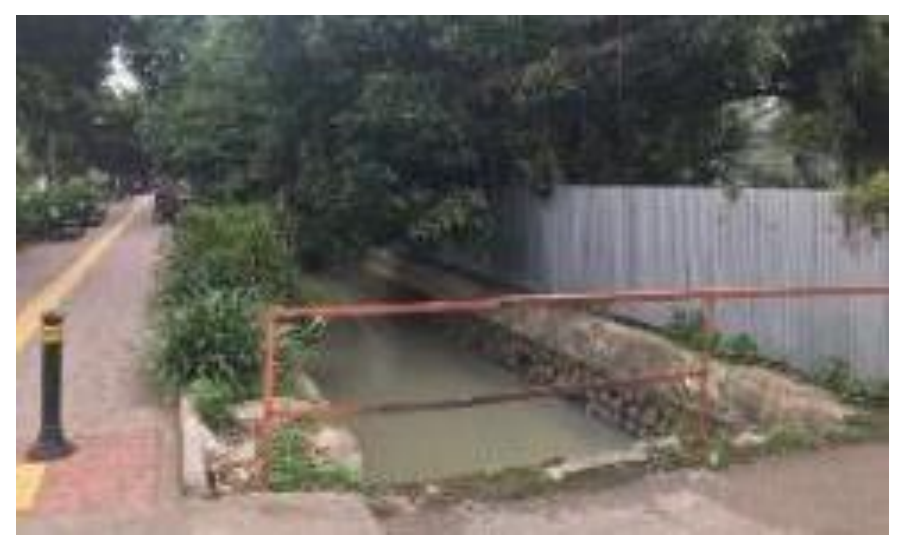

Gambar 9. Kondisi kali di depan tapak Sumber: Penulis, 2019

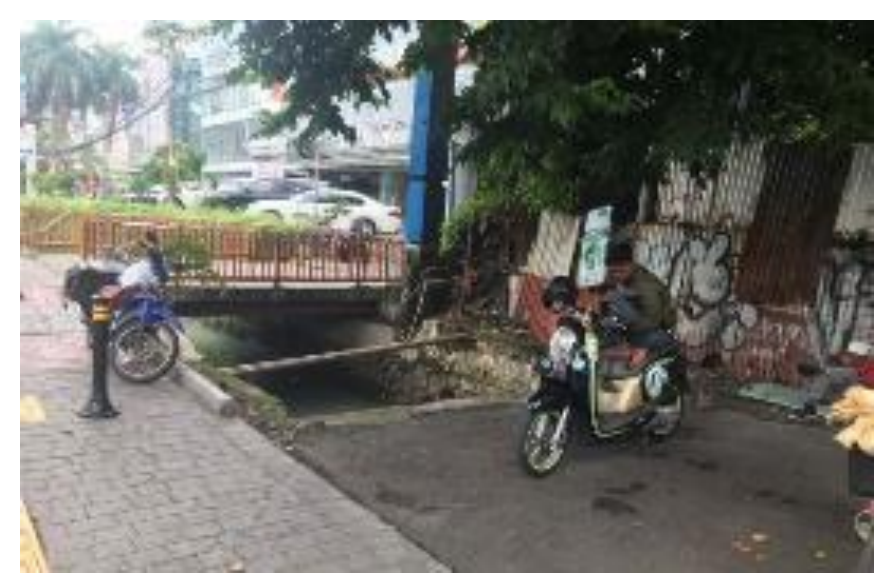

Gambar 10. Kondisi entrance di depan tapak Sumber: Penulis, 2019

Tapak bangunan Millennial Hall ini terdapat di tanah kosong yang berhadapan dengan jalan utama yaitu Jl. Kyai Tapa di sisi Utara, Jl. Tawakal II A di sisi Selatan, Apartemen The Gloria Suites di sisi Timur dan Sekolah Tinggi Manajemen Trisakti di sisi Baratnya. Dengan luas mencapai 1 hektar.

\section{Metode Perancangan Tipologi}

\section{a. Studi Teori}

- Teori dan program ruang exhibition hall dan creative hub

- Studi tipologi exhibition hall

- Peraturan pemerintah setempat

\section{b. Studi Kasus}

Melakukan studi pada bangunan dengan fungsi dan tipologi yang serupa dan mengambil program maupun gubahan yang dapat digunakan kedalam bangunan.

\section{c. Studi Site}

Melakukan studi langsung terhadap tapak yang akan dibangun untuk mengetahui kondisi fisik maupun non-fisik yang terdapat pada tapak.

\section{d. Analisis Data}

Melakukan analisis dan sintesis terhadap data-data yang telah didapat hingga mendapat kesimpulan hasil untuk dimasukkan kedalam rancangan bangunan. 


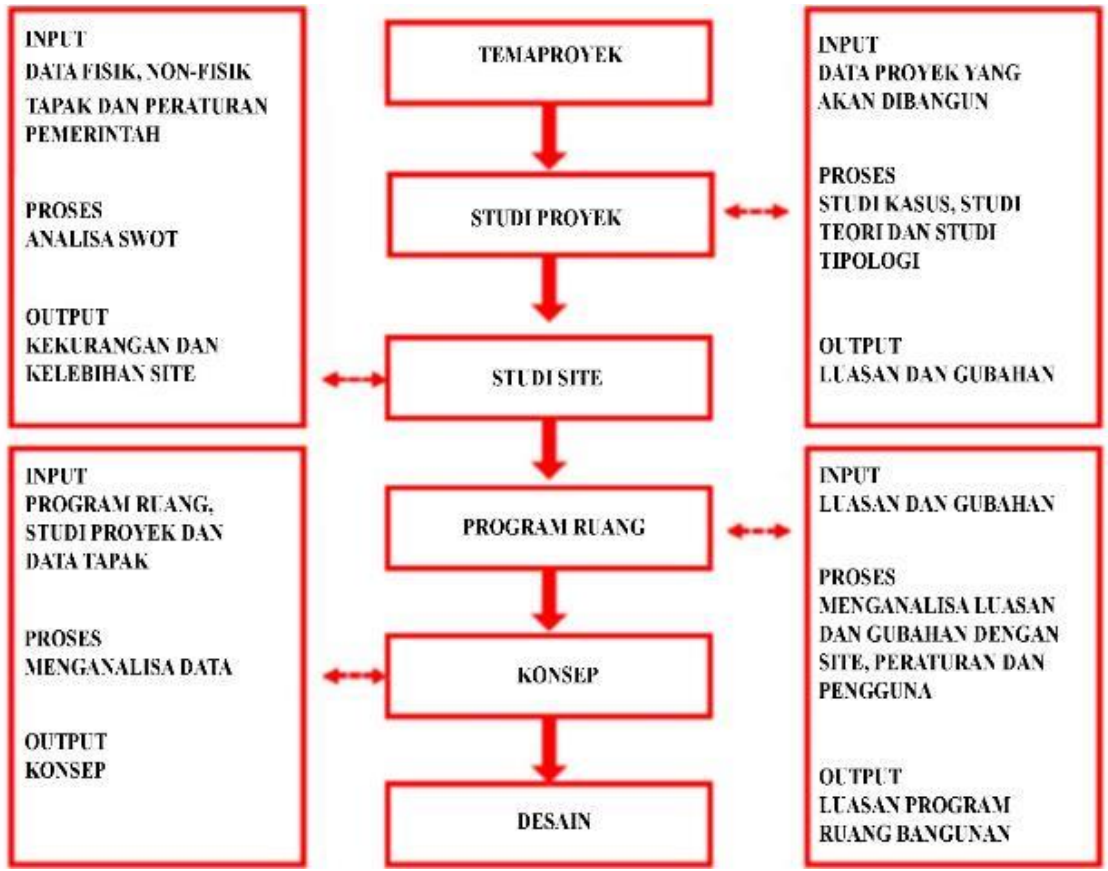

Gambar 11. Kerangka Pikir Sumber: Penulis, 2019

\section{DISKUSI DAN HASIL}

Data-data yang telah didapati kemudian di analisa dan di proses sebagai berikut :

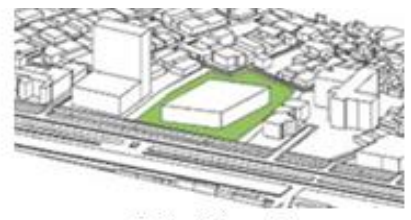

Design scheme 1

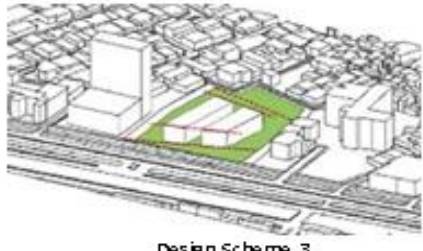

Design Scheme

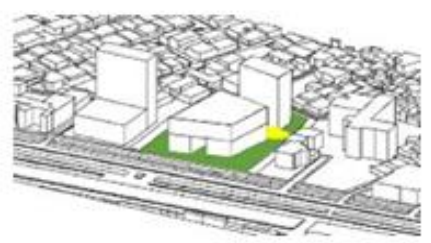

Desien scheme 5

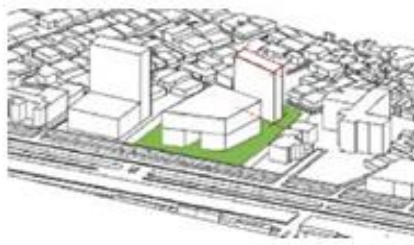

Design Scheme 7
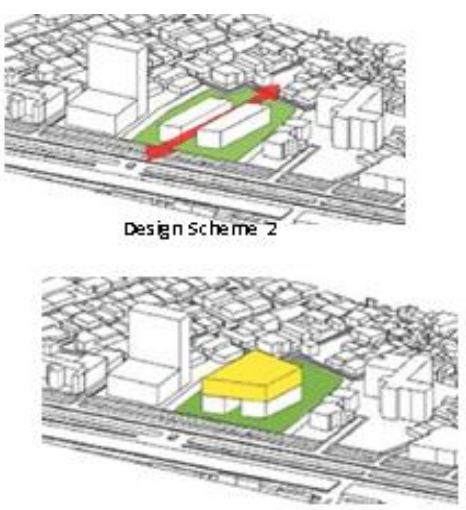

Design Scheme 4

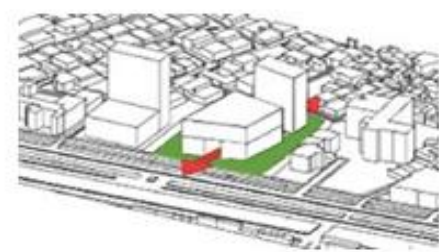

Design Scheme 6

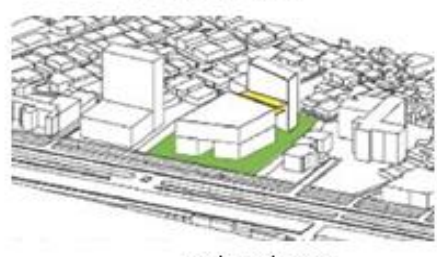

Design Scheme 8

Gambar 12. Design Schemes

Sumber: Penulis, 2019 
Design Schemes meliputi :
a. 1.Blok massa awal
b. 2.Blok massa terbelah oleh akses pedestrian dari jalan lokal (JI. Tawakal IIA) menuju jalan arteri (JI. Kyai Tapa) dan sebaliknya.
c. 3.Bentukan massa bangunan mengikuti bentukan tapak dan sisi bangunan yang lebih lebar menghadap ke sisi timur sedangkan yang lebih kecil menghadap ke sisi barat.
d. 4.Lantai atas bangunan masif untuk memenuhi tipologi dan kapasitas hall.
e. 5.Massa hall dengan tower dipisah untuk menciptakan ruang publik diantara kedua massa tersebut yang juga menjadi meeting point.
f. 6.Lantai dasar massa tower juga ikut terbelah mengikuti axis sirkulasi tapak.
g. 7.Bentuk massa tower mengikuti bentukan tapak.
h. 8.Atap kanopi untuk mewadahi ruang publik diantara kedua massa bangunan.

Dari hasil proses desain tersebut didapati hasil akhir berupa 2 massa terpisah yang memiliki ruang publik diantara keduanya seperti berikut:

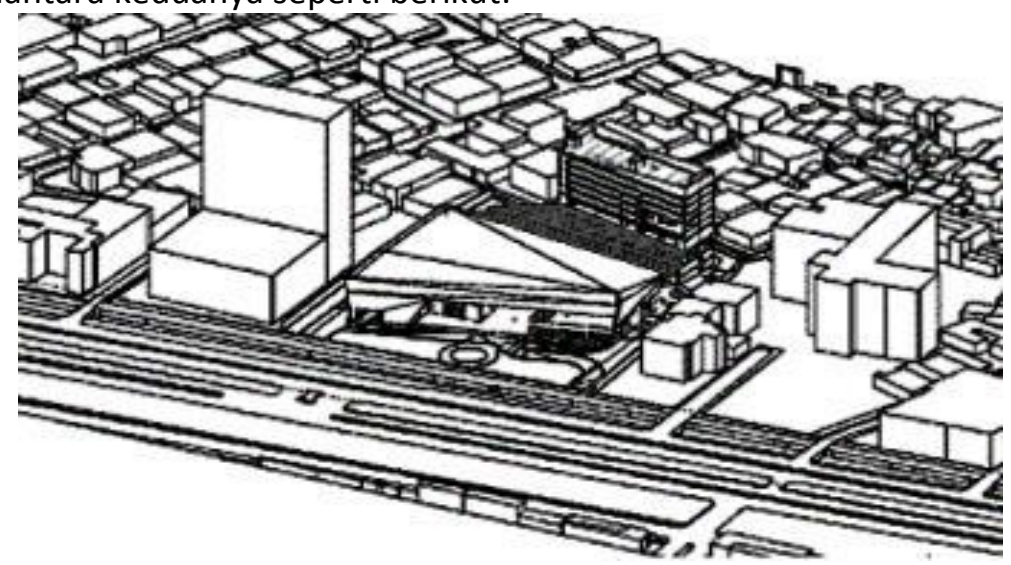

Gambar 13. Hasil Akhir Massa Bangunan Sumber: Penulis, 2019

Setelah didapati massa akhir bangunan tersebut, berulah dimasukkan program ruang kedalam massa tersebut hingga akhirnya didapati hasil sebagai berikut ini:

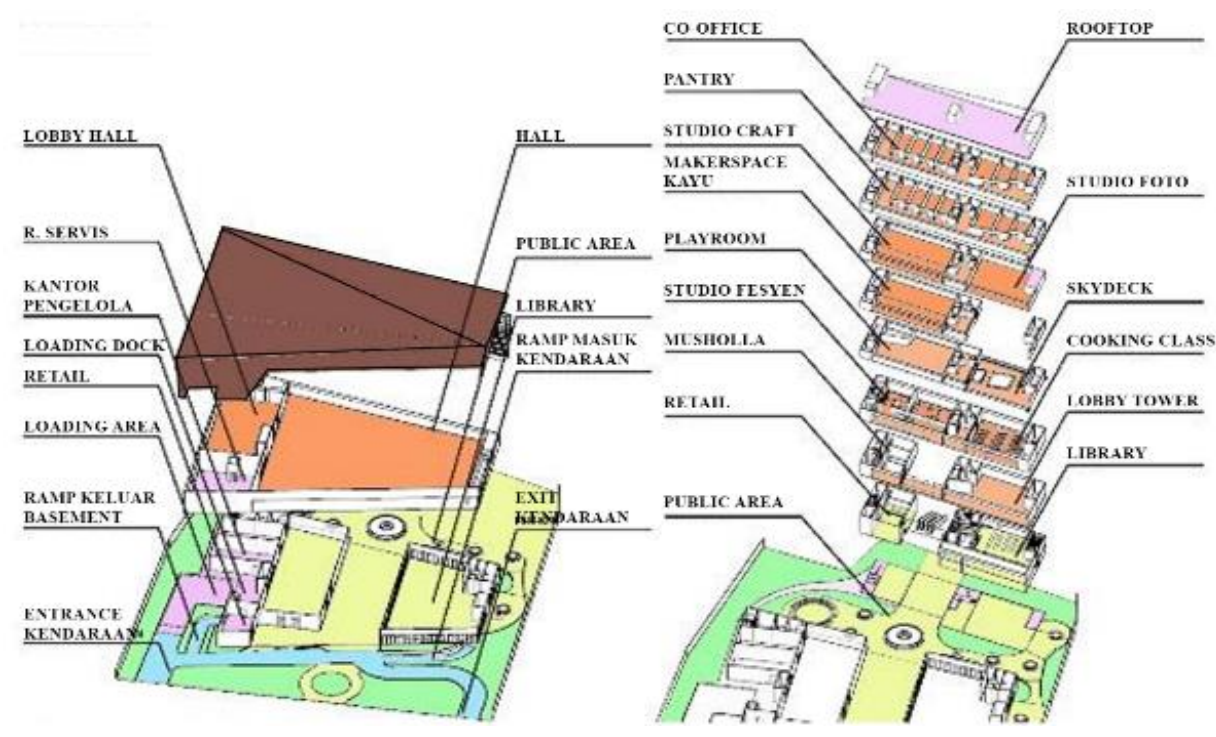

Gambar 14. Hasil Akhir Massa Bangunan

Sumber: Penulis, 2019 


\section{KESIMPULAN DAN SARAN}

\section{Kesimpulan}

Untuk menjawab permasalahan milenial dan memberikan wadah bagi mereka untuk mengembangkan diri dan mengekspresikan kreativitas mereka, maka dibentuklah Millennial Hub ini yang juga berfungsi untuk menampung segala kegiatan penduduk milenial dan nonmilenial.

Dengan adanya Millennial Hub ini, maka diharapkan bangunan ini dapat menampung penduduk sekitar baik generasi milenial maupun non-milenial yang memiliki kreativitas tinggi untuk dapat mengembangkan dan mengekspresikan kreativitasnya hingga akhrinya dapat turut berkontribusi dalam industry kreatif yang bertujuan untuk meningkatkan ekonomi kreatif baik dalam skala nasional maupun internasional.

Hall yang dahulunya memiliki fungsi untuk sesuatu yang bersifat spesifik, sekarang telah berubah menjadi Millennial Hall dimana hall ini utamanya difungsikan bagi generasi milenial dimana generasi milenial membutuhkan ruang yang lebih fleksibel sehingga Millennial Hall ini mengikuti kebutuhan milenial tersebut.

Saran

Bagi peneliti selanjutnya disarankan agar lebih dalam dalam mencari hubungan antar ruang dengan generasi millennial agar didapati kebutuhan ruang yang relefan baik dari luasan hingga ruang arsitekturalnya bagi generasi millennial tersebut.

\section{REFERENSI}

Ali, H. (2019, 3 Januari) "Generasi Millennial Indonesia: Tantangan dan Peluang Pemuda Indonesia". http://alvara-strategic.com/generasi-millennial-indonesia-tantangan-danpeluang-pemuda-indonesia/

Armstrong, M. (2017, 26 Juni). "War of the Words: Millenials vs. Baby Boomers".

https://www.statista.com/chart/9959/war-of-the-words_-millenials-vs-baby-boomers/

Bardram, J. (2004). Architectural Prototyping: An Approach for Ground Architectural Design and Learning. Denmark:University of Aarhus

DesMarais, C. (2019, 5 Januari). "27 Experts Tips for Marketing to Millennials". https://www.inc.com/christina-desmarais/27-expert-tips-for-marketing-to-millennials.html

Farrington, R. (2019, 8 Januari). "What is The Millennial Age Range and What Does That Mean Financially?". https://thecollegeinvestor.com/19793/millennial-age-range/

Hamling, S. (2019, 4 Januari). "How to Market to Millenials: 5 Brands Who are Doing it Right". https://artplusmarketing.com/how-to-market-to-millennials-5-brands-who-are-doing-itright-9273d35b43cf

Johansson, A. (2019, 2 Januari). "Why Millennials Are Introducing Creativity To Diversity And Inclusion Programs". https://www.forbes.com/sites/annajohansson/2017/09/12/whymillennials-are-introducing-creativity-to-diversity-and-inclusion-programs/

Kane, S. (2019, 28 Mei). "The Common Characteristics of Millenial Professionals".

https://www.thebalancecareers.com/common-characteristics-of-generation-y-professionals2164683

Kemenristekdikti. (2019, 13 Februari). "Kemenristekdikti Siapkan SDM Milenial Indonesia Kreatif, Inovatif, dan Berdaya Saing Tinggi". https://www.ristekdikti.go.id/kabar/kemenristekdikti-siapkan-sdm-milenial-indonesiakreatif-inovatif-dan-berdaya-saing-tinggi/

Klam, A.(1980). Space and Material: Towards An Architectural Typology. Paris: Massachusetts Institute of Technology

Lucas, R. (2019, 24 Juni) "If you work in the creative industries you're in business". 
https://www.edinburghnews.scotsman.com/news/opinion/if-you-work-in-the-creativeindustries-you-re-in-business-robert-lucas-1-4952175

Moneo, R. (1978). Oppositions. The Institute for Architecture and Urban Studies

Mahrizal, V. (2019, 5 Januari). "Bekraf Siapkan Rp630 Miliar untuk Pelaku Ekonomi Kreatif di 2019". http://jogja.tribunnews.com/2019/01/22/bekraf-siapkan-rp630-miliar-untukpelaku-ekonomi-kreatif-di-2019

Merina, N. "Apa Ekonomi Kreatif dan Potensi Besar Bagi UKM". http://goukm.id/ekonomikreatif/

Nadia, C. (2019, 7 Januari) "Data Statistik dan Hasil Survei Khusus Ekonomi Kreatif". 7 Januari 2019. http://www.bekraf.go.id/pustaka/page/data-statistik-dan-hasil-survei-khususekonomi-kreatif

Purwandi, L. (2019, 12 Februari) "Indonesia 2020: The Urban Middle Class Millenials"..https://www.researchgate.net/publication/314448735_Indonesia_2020_The_U rban_Middle_Class_Millenials

Suhariyanto. (2017). Tenaga Kerja Ekonomi Kreatif 2011-2016. Jakarta: Badan Ekonomi Kreatif

Suharjanto, G. Keterkaitan Tipologi Dengan Fungsi Dan Bentuk: Studi Kasus Bangunan Masjid. Jakarta: Binus University

Tatyana, I. (2019, January 03). Infografis Ringkasan Data Statistik Ekonomi Kreatif Indonesia. http://www.bekraf.go.id/berita/page/9/83-infografis-ringkasan-data-statistik-ekonomikreatif-indonesia

Tumoutou. (2019, January 03). Jumlah Penduduk DKI Jakarta Tahun 2018. https://tumoutounews.com/2018/12/05/jumlah-penduduk-dki-jakarta-tahun-2018/

United Nation. (2019, January 4). Sustainable Development Goals. https://www.un.org/sustainabledevelopment/sustainable-development-goals/ 